\title{
Familial microscopic colitis
}

\author{
Ayman Assad Abdo MD ${ }^{1}$, Peter Jeffrey Zetler $\mathrm{MD}^{2}$, Lawrence S Halparin MD FRCP 3
}

\begin{abstract}
AA Abdo, PJ Zetler, LS Halparin. Familial microscopic colitis. Can J Gastroenterol 2001;15(5):341-343. Collagenous and lymphocytic colitis are two inflammatory conditions of the colon that are often collectively referred to as microscopic colitis. The present report describes what is believed to be the third published case of familial microscopic colitis. A 55-year-old woman who suffered from chronic diarrhea was diagnosed with lymphocytic colitis on colonic biopsy. Subsequently, her 36year-old daughter was diagnosed with collagenous colitis. The familial occurrence of these diseases may support an immunological hypothesis for their etiology. In addition, it supports the assumption that collagenous and lymphocytic colitis are two manifestations of the same disease process rather than two completely separate entities. The familial tendency of this disease may make a case for early colonoscopy and biopsy in relatives of patients diagnosed with microscopic colitis if they present with suggestive symptoms.
\end{abstract}

\section{Colite microscopique familiale}

RÉSUMÉ : La colite collagène et la colite lymphocytaire sont deux affections inflammatoires du côlon souvent considérées comme une forme de colite microscopique. Le présent article fait état du troisième cas publié, croit-on, de colite microscopique familiale. Il s'agit d'une femme de 55 ans, souffrant de diarrhée chronique, chez qui un diagnostic de colite lymphocytaire a été posé à la suite d'une biopsie du côlon. Plus tard, une colite collagène a été diagnostiquée chez sa fille de 36 ans. L'apparition de ces deux maladies dans la même famille tend à confirmer non seulement l'hypothèse de l'étiologie immunitaire mais aussi le fait que la colite collagène et la colite lymphocytaire seraient deux manifestations d'un même processus morbide plutôt que deux maladies totalement distinctes. Comme l'affection semble avoir des tendances familiales, il serait peut-être approprié que les parents des patients chez qui une colite microscopique a été diagnostiquée subissent une coloscopie et une biopsie précoces s'ils en présentent des symptômes révélateurs.

Key Words: Collagenous colitis; Microscopic colitis

C ollagenous colitis (CC) and lymphocytic colitis (LC) are two inflammatory conditions of the colon that are often referred to as microscopic colitis. They are of unknown etiology and occur more commonly in middle-aged and elderly women. They are characterized by watery diarrhea and sometimes additional nonspecific symptoms that usually extend over a period of time (1). Endoscopic examination of the colon is normal, and the diagnosis is histological.

Due to the relative rarity of these forms of colitis, reliable studies of treatment options are scanty. Retrospective studies show that sulphasalazine, 5-aminosalicylic acid, local and systemic steroids, and nonspecific antidiarrheal agents have been tried with various success rates. Small prospective, randomized trials have shown efficacy of bismuth (2).

The present paper reports the cases of a mother and her daughter with LC and CC, respectively.

\section{CASE PRESENTATIONS}

The mother: A 55-year-old woman, originally from Iran, presented initially with vague abdominal symptoms that she had experienced for many years. She had some abdominal cramps in the periumbilical region associated with occa-

${ }^{1}$ Department of Medicine, University of British Columbia; ${ }^{2}$ St Paul's Hospital; ${ }^{3}$ University of British Columbia, and Division of Gastroenterology, St Paul's Hospital, Vancouver, British Columbia

Correspondence: Dr Lawrence Halparin, 507-1160 Burrard Street, Vancouver, British Columbia V6Z 2E8. Telephone 604-682-8224, fax 604-682-5372, lhalparin@interchange.ubc.ca

Received for publication October 21, 1999. Accepted May 18, 2000 


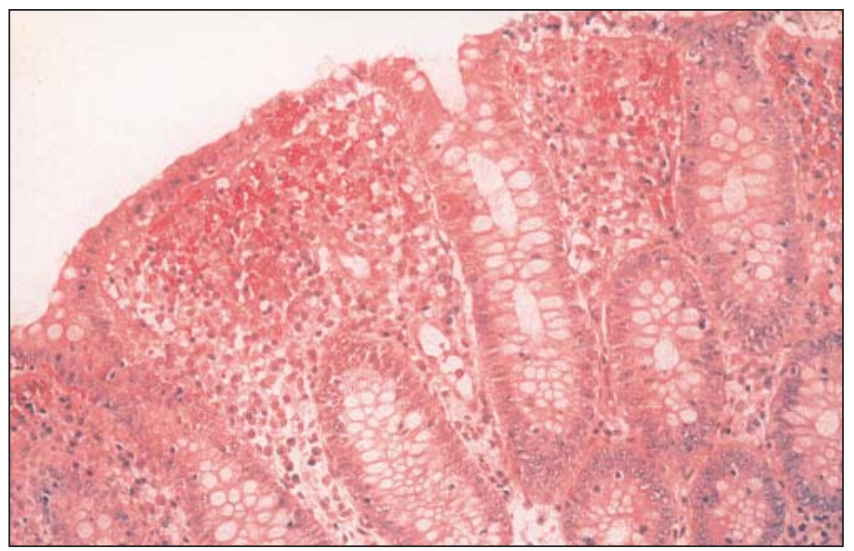

Figure 1) Colonic biopsies of the mother showing features of lymphocytic colitis

sional periods of diarrhea, which were diagnosed as irritable bowel syndrome. She was taking hormone replacement therapy and propranolol for migraines. Otherwise, she was healthy and had no significant past medical history. There was a strong family history of peptic ulcer disease. Her physical examination, including a rectal examination, was entirely normal. Stool samples tested negative for occult blood and only grew normal colonic flora. The patient's level of thyroid-stimulating hormone was normal.

One year later, the patient's symptoms recurred together with increased stress levels; this time, the patient suffered from slightly increased bloating and more frequent attacks of diarrhea. She also reported some dysphagia. Upper gastrointestinal endoscopy results were normal, including normal biopsies from the small bowel; flexible sigmoidoscopy results were also normal. No biopsies were taken. Because of persistent bloating and cramps, a small bowel follow-through was performed and was normal. Over the next four years, the patient continued to have recurring symptoms that partially responded to ranitidine. A repeated upper gastrointestinal endoscopy was performed, and was normal; results of a barium enema were also normal. An upper gastrointestinal series was completed, which showed evidence of reflux and a small sliding hiatus hernia. She was then treated with cisapride with some improvement. About two years later she developed more diarrhea (up to three times a day), which was watery, nonbloody and associated with some urgency. She continued to have cramps. Flexible sigmiodoscopy was performed and was normal. Biopsies of the sigmoid colon showed evidence of LC (Figure 1). She was placed on 5 aminosalicylic acid (Asacol, Procter \& Gamble Pharmaceuticals, Canada) $1200 \mathrm{mg}$ bid, and her bowel movements returned to normal. Six months later, her symptoms remained under good control.

The daughter: A 36-year-old woman had a long standing history of intermittent diarrhea and constipation; she also reported some nonspecific abdominal cramps. The patient was diagnosed with irritable bowel syndrome in England. She had no rectal symptoms or rectal bleeding. She had no symptoms of peptic ulcer disease but did report occasional heart-

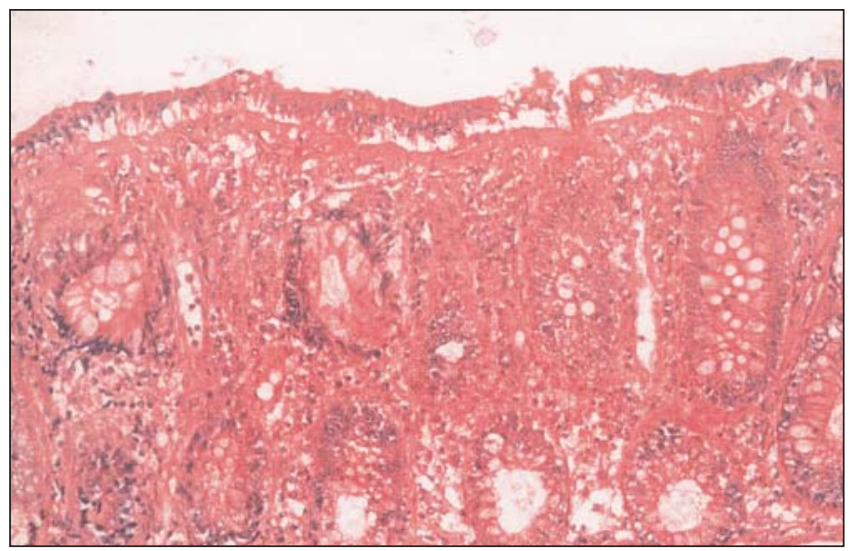

Figure 2) Colonic biopsies of the daughter showing features of collagenous colitis

burn. She had no weight loss or lactose intolerance, and there was no recent travel or recent antibiotic use. She was not on any medications, and her past medical history was not significant. She was a smoker and an occasional drinker, and there was a family history of peptic ulcer disease. Physical examination was unremarkable. Results from complete blood counts and stool examinations were normal. One year later, her symptoms worsened, with more diarrhea and increased urgency. Colonoscopy was normal, but random biopsies of the colon showed CC (Figure 2). She was treated with Asacol $800 \mathrm{mg}$ tid, and her diarrhea completely resolved.

\section{DISCUSSION}

We believe that the present report is the third case report in the English language literature of microscopic colitis occurring in first-degree relatives.

In 1976, Class Lindstrom (3) published a case of a 48year-old woman with chronic watery diarrhea who showed remarkable subepithelial collagenous deposit in a rectal biopsy specimen. This was probably the first case report of this entity. By the end of 1996 (20 years later), more than $500 \mathrm{CC}$ (4) and $60 \mathrm{LC}$ cases had been described.

Despite the increasing number of cases, we found only two previous reports of familial colitis in the published English language literature. In the first report, two families were described. In one family, two sisters were affected with chronic watery diarrhea and autoimmune disorders. CC was diagnosed in one of the sisters. Colonic biopsy of the other sister showed microscopic colitis, and review of colonic biopsies from this patient 11 years earlier showed CC. In the other family, a father and son both suffered from chronic diarrhea, and CC was diagnosed in both. Human leukocyte antigen (HLA) typing showed that only the HLA A2 was present in all four patients (5).

In the second report, a 13-year-old girl and her father were both diagnosed with celiac disease after a chronic illness of diarrhea and weight loss. Both father and daughter had changes consistent with CC on colonic biopsy (6).

The exact etiology of microscopic colitis is not yet fully understood; an autoimmune pathogenesis in CC has been 
suggested (7). Inflammation initiated by a foreign luminal agent, eventually leading to immunological cross-reactivity with an endogenous antigen produced by surface enterocytes, has been proposed (8). This theory is supported by the frequent association of $\mathrm{CC}$ with autoimmune diseases, the high prevalence of fecal leukocytes and clinical response to antiinflammatory agents. In the case of $\mathrm{LC}$, the pathogenesis is less clear, but again, the inflammatory process is thought to be immune-mediated, given the high incidence of autoantibodies and other immune-mediated conditions (9).

In view of the above postulated pathogenesis, it would not be surprising to note some familial tendency in these conditions - many other more established autoimmune diseases have been shown to run in families.

Also in support of a possible immunological pathogenesis, immunological studies showed that, in LC patients, compared with controls, HLA A1 was significantly increased in frequency and HLA A3 was decreased in frequency. CC patients had no significant HLA differences compared with controls (10).

In our report, the mother's biopsies showed LC, while the daughter's biopsies showed CC. Whether the two diseases are completely separate but related or are two manifestations of the same disease is still a matter of debate. Early in 1986, Jessurun et al (11) described these debated views as 'lumpers' and 'splitters', and argued for the 'lumpers' group. Several groups have supported this opinion (8). Their argument was based on the fact that the two diseases have a high degree of similarity in clinical, laboratory and histological findings, and they may occur in the same patient at different times during the course of the disease (12). Investigators who believe that the two diseases are completely different but related entities support their argument by the fact that the two diseases have a different female to male ratio, the absence of a subepithelial collagen layer in LC and the observed HLA differences (13).

Reports of a gradual transition from LC to CC (14) and reports observing the two diseases in the same family (including our report) support the assumption that CC and $\mathrm{LC}$ are similar and related diseases.

van Tilburg et al (5) noted that HLA A2 was found in all four of the patients from the two families that they studied, and HLA A1 was found in two patients. In our report, HLA A2 was not found in either of the two patients. However, HLA A1 and HLA B7 were present in both the mother and the daughter. It has to be noted that all four patients described by van Tilburg had been diagnosed with CC, while in our study, the mother had LC and the daughter had CC. Because of the rarity of the reported cases with familial occurrence, it is difficult to make conclusions in regarding this variability in HLA patterns.

Obviously, it is almost impossible to prove absolutely the familial tendency of such uncommon diseases, but we believe that with the recent increased awareness of microscopic colitis, more biopsies will be taken from normalappearing colons. This will probably increase the number of diagnoses for these diseases, and the familial tendency may become more apparent.

\section{CONCLUSIONS}

The present report describes what is believed to be the third reported case of familial microscopic colitis in the literature. This may suggest that early colonoscopy and biopsy should be performed in relatives of patients diagnosed with microscopic colitis, if the patients present with chronic diarrhea.

\section{REFERENCES}

1. Zins B, Sandborn W, Tremaine WJ. Collagenous and lymphocytic colitis: Subject review and therapeutic alternatives. Am J Gastroenterol 1995;90:1394-1400.

2. Fine KD, Lee EL. Efficacy of open-label bismuth subsalicylate for the treatment of microscopic colitis. Gastroenterology 1998;114:29-36.

3. Lindstrom CG. Collagenous colitis with watery diarrhea - a new entity? Pathol Eur 1976;11:87-9.

4. Bohr J. A review of collagenous colitis. Scand J Gastroenterol 1998;33:2-9.

5. van Tilburg AJ, Lam HG, Seldenrijk CA, et al. Familial occurrence of collagenous colitis: A report of two families. J Clin Gastroenterol 1990:12:279-85.

6. Perisic VN, Kokai G, Pavlovic M. Coeliac disease and collagenous colitis. Ital J Gastroenterol 1992;24:418-20.

7. Armes J, Gee DC, Macrae FA, Schroeder W, Bhathal PS. Collagenous colitis: jejunal and colorectal pathology. J Clin Pathol 1992:45:784-7.

8. Bayless TM, Giardiello FM, Lazenby A, Yardley JH. Collagenous colitis. Mayo Clin Proc 1987;2:740-1.

9. Giardiello FM, Lazenby AJ, Bayless TM, et al. Lymphocytic (microscopic colitis): Clinicopathological study of 18 patients and comparison to collagenous colitis. Dig Dis Sci 1989;34:1730-8.

10. Giardiello FM, Lazenby AJ, Yardley JH, et al. Increased HLA A1 and diminished HLA A3 in lymphocytic colitis compared to controls and patients with collagenous colitis. Dig Dis Sci 1992;37:496-9.

11. Jessurun J, Yardley JH, Lee EL, Vendrell DD, Schiller LR, Fordtran JS. Microscopic and collagenous colitis: different names for the same condition? Gastroenterology 1986;91:1583-4. (Lett)

12. Carpenter HA, Tremaine WH, Batts KP, Czaja AJ. Sequential histologic evaluations in collagenous colitis. Dig Dis Sci 1992;37:1903-9.

13. Wang KK, Perrault J, Carpenter HA, Schroeder KW, Tremaine WJ. Collagenous colitis: a clinicipathological correlation. Mayo Clin Proc 1987;62:665-71.

14. Palmer KR, Berry H, Wheeler PJ, et al. Collagenous colitis a relapsing and remitting disease. Gut 1986;27:578-80. 


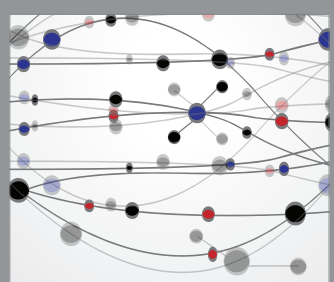

The Scientific World Journal
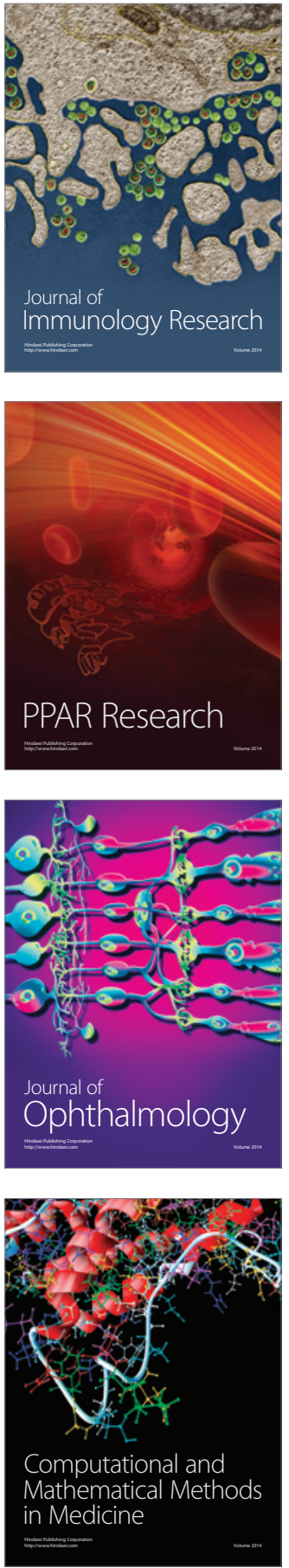

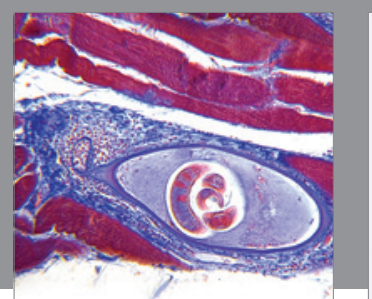

Gastroenterology Research and Practice

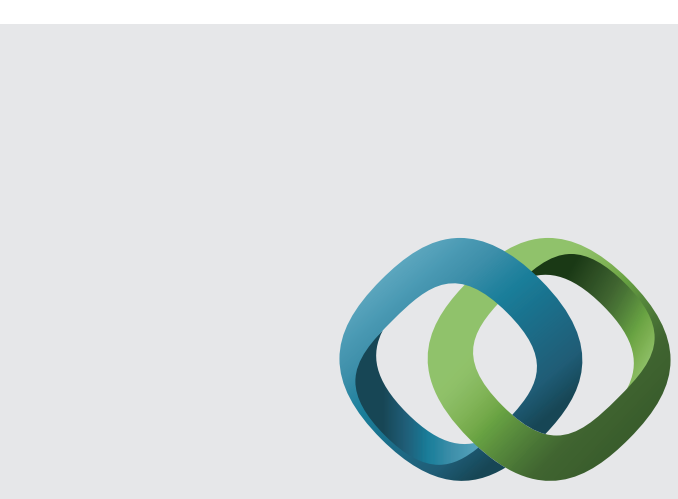

\section{Hindawi}

Submit your manuscripts at

http://www.hindawi.com
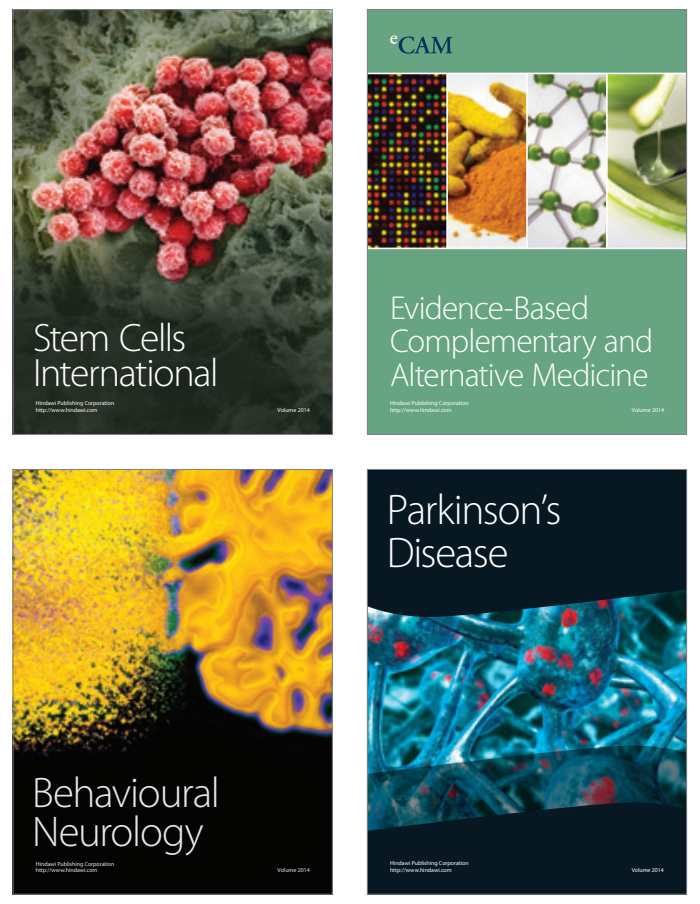
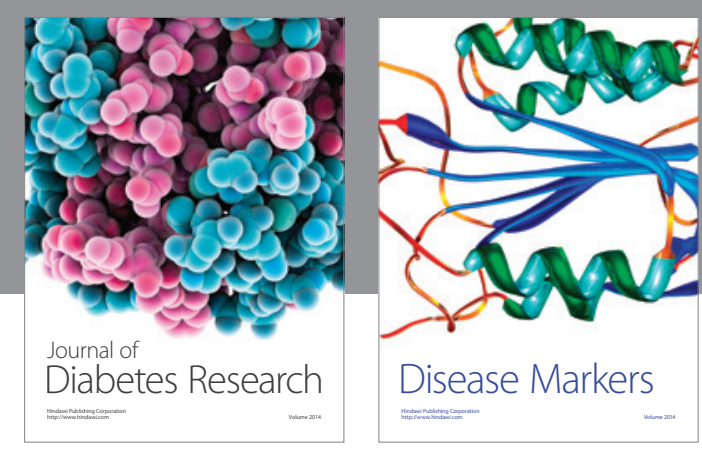

Disease Markers
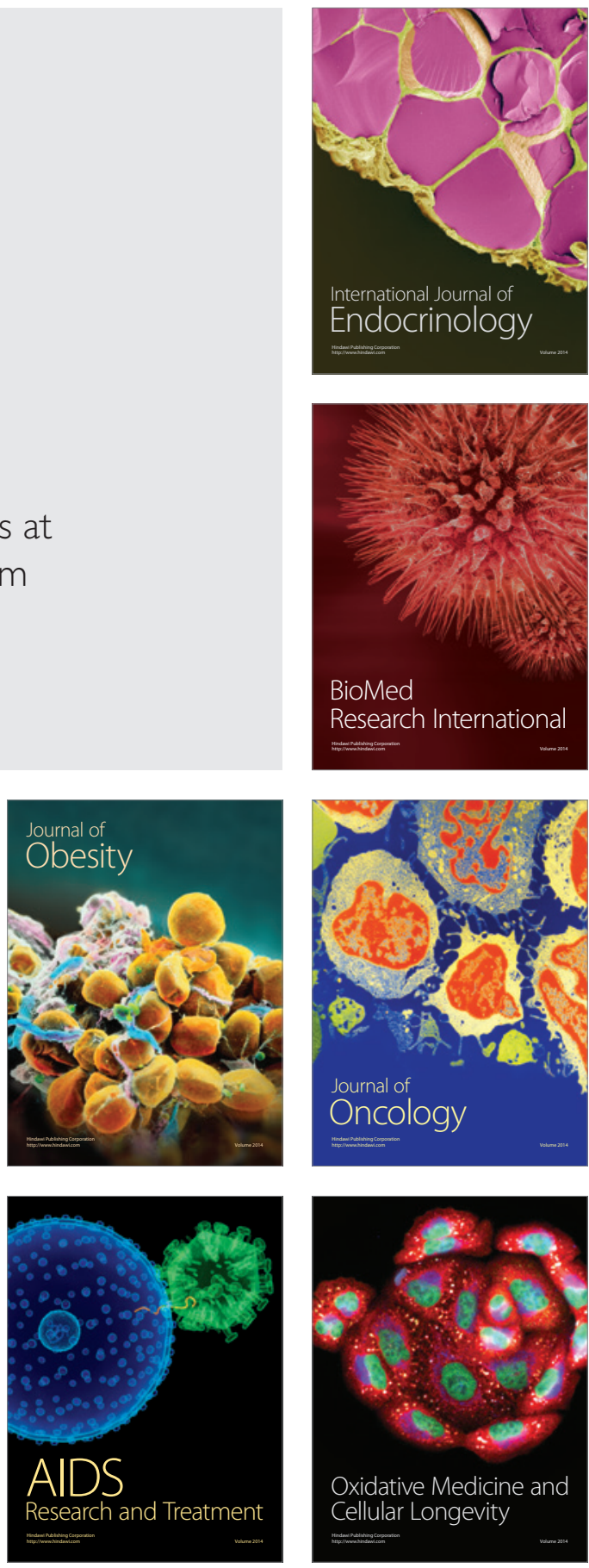